\title{
Are Family Transfers Crowded Out by Public Transfers?*
}

\section{Werner Güth}

Max Planck Institute for Research into Economic Systems, D-07745 Jena, Germany gueth@mpiew-jena.mpg.de

\section{Theo Offerman}

University of Amsterdam, NL-1018 WB Amsterdam, The Netherlands

theoo@fee.uva.nl

\section{Jan Potters}

Tilburg University, NL-5000 LE Tilburg, The Netherlands

Potters@uvt.nl

\section{Martin Strobel}

University of Maastricht, NL-6200 MD Maastricht, The Netherlands

m.strobel@merit.unimaas.nl

\section{Harrie A. A. Verbon}

Tilburg University, NL-5000 LE Tilburg, The Netherlands verbon@uvt.nl

\begin{abstract}
We give an account of an overlapping-generations experiment with multiple families in which voluntary transfers can take the form of support to the elderly or grants to children. Support to the old is a purely intergenerational (intra-family) transfer, whereas grants to children also involve an element of intra-generational (inter-family) redistribution through a compulsory pension system. Our data show that higher compulsory inter-family transfers lead subjects to place relatively more emphasis on support instead of grants: grants are crowded out, but support is not significantly affected. The efficiency of voluntary transfers increases, however. Furthermore, if subjects give transfers, they do not use tokens of direct reciprocity; evidence of indirect reciprocity in transfer behavior can only be obtained for the case where compulsory transfers are high.
\end{abstract}

Keywords: Experiments; within-family transfers; overlapping generations; redistributive public-pension system; crowding out; reciprocity

JEL classification: C91; H55

\footnotetext{
${ }^{*}$ We are grateful for helpful comments by Pierre Pestieau, Jan Nelissen and two referees. We would like to thank Klaus Abbink and Abdolkarim Sadrieh for the RatImage Toolbox, which we used to implement the experiment software; see Abbink and Sadrieh (1995). Potters acknowledges a fellowship from the Academy of Arts and Sciences, the Netherlands. 


\section{Introduction}

Voluntary transfers between parents and children are a major factor in the allocation of income and wealth. Parents invest time and money in raising their children, and they help them with gifts, college tuition and grants. According to Kotlikoff (1988), intergenerational transfers from parents to adult children are estimated to involve as much as 80 percent of total assets in the U.S. of which about 50 percent are inter vivos; see Gale and Scholz (1994). Children, on the other hand, not only spend time and energy in attention and care of their parents, they also provide them with old age support. For example, McGarry and Schoeni (1995) use data from the Health and Retirement Study to observe that 7.1 percent of adult children make financial transfers to their parents.

The explanation for these voluntary transfers is not a well-established matter. Two types of explanations stand out. One type relies on altruism that arises from kinship; see Becker (1974). You are kind to your kin, because you care about their well-being. The other explanation relies on some form of quid pro quo or reciprocity. You are kind to your parents in reaction to their kindness. In this case, contrary to altruism, transfers are of a conditional nature, as in Bernheim, Shleifer and Summers (1985), Cigno (1993), Cox (1987) and Hammond (1975). Such conditionality, however, can come in different shapes. One is direct reciprocity, according to which you are kind to your parents in relation to how kind they are to you. Another is indirect reciprocity, according to which you are kind to your parents in response to how kind they have been to their parents.

Understanding the motives behind voluntary intergenerational transfers is important as different motives may imply different responses to public transfers. If transfers are motivated by altruism, an increase in tax-financed old age transfers will crowd out private transfers to parents dollar-for-dollar because of the Ricardian-equivalence effect. For the same reason, transfers from parents to children will increase in order to compensate for the income effect of public transfers. If, however, transfers are motivated by a reciprocity motive, the effects of an increase in tax-financed old age transfers are not so clear. One possibility is that the level of voluntary transfers will decrease (though typically not dollar-for-dollar). Since the elderly receive a public pension there is less need for private old age support from children. To the extent that parents in their old age still require support from their children, however, engendering the same level of support through reciprocity may require a higher level of transfers from parent to child if a larger part of the latter transfers is taxed.

The degree to which crowding out occurs is difficult to investigate due to lack of adequate data. In one of the few empirical studies, Künnemund and Rein (1999) found little support for crowding out of transfers from children 
to parents. This suggests that altruism is not the main, or at least not the sole, motive for voluntary transfers. Although based on only one study, this conclusion would be in line with several other empirical studies which have tested and rejected other predictions of the altruism model; see e.g. Altonji, Hayashi and Kotlikoff (1997), Cigno, Gianelli and Rosati (1998) and Cox and Rank (1992).

Here, we examine crowding out in an experimental setting; see also Bolton and Katok (1998) and Cadsby and Frank (1990). One advantage is that experiments provide detailed information on individual behavior and make it possible to isolate the effect of a key variable, in this case the expansion of tax-financed old age support. Furthermore, since the experiments were conducted with students as subjects, altruistic motives derived from kinship will be minimal. Although the presence of altruism can still not be excluded, voluntary transfers in the laboratory are more likely to derive from reciprocity. We can thus gain a better understanding of the behavioral regularities of reciprocity-motivated transfers.

We implemented an experimental design with two "families" coexisting at the same time in which every subject has one "child" and one "parent". Intertemporal consumption smoothing cannot be achieved by savings. Instead, the experimental subjects were supplied with two instruments. One instrument, called support, involves an intra-family intergenerational transfer from child to parent. The other instrument, called grant, involves a transfer in the opposite direction, from parent to child. The grant increases the income-earning capacity of the child. In line with this, grants are added to the wage income children earn when entering adulthood. Total adult income (wage plus grants) is taxed on behalf of a compulsory pension of the pay-asyou-go variety. So, the pension scheme is a collective scheme, redistributing income from the present young (working) generation to the present old (retired) generation, involving both families. Therefore, grants also imply an intra-generational (inter-family) redistribution: a positive grant increases not only one's own pension, but also that of one's contemporary in the other family. As a result, a free-rider problem is involved: subjects might tend to avoid inter-family redistribution by relying less on investments in children and more on old age support if the tax rate increases. Unlike grants, supports are purely intergenerational transfers, which do not interfere with the pension system and leave the other family's welfare untouched.

At the time an adult child decides about support to his or her parent, the child has a wage income and the parent is in old age and has no wage income. Support can then be used to smooth consumption across generations. One way in which a chain of intergenerational support could be sustained is by means of indirect reciprocity. For example, the rule could be to support the parent to the same extent that the parent supported her or his parent. This type of quid pro quo was studied experimentally by Offerman, 
Potters and Verbon (2001) and Van der Heijden, Nelissen, Potters and Verbon (1998) and found to receive only weak support. These studies, however, were limited to a one-family context and did not allow for grants, that is, transfers from parent to child.

As grants are taxed and used to finance the pension benefit, a grant automatically smoothes consumption to some extent. A grant raises the child's income and thereby the tax revenues and the collective pension benefit of his or her parent. However, as grants are only partly returned, depending on the level of the tax rate, they are a (much) less effective consumption-smoothing device than support. In addition to smoothing consumption directly, however, a grant from parent to child may be used to elicit old age support from child to parent later on. There is growing evidence that direct reciprocity is important in many interactions; see Fehr and Gächter (2000) for a survey. People tend to repay kindness with kindness. In the present context the child could repay a grant with (old-age) support.

The treatment variable in our experiments is the pension tax rate, which can be low or high. This enables us to investigate the following questions: Will grants or support be used mainly as an income-smoothing device? To what extent will increasing government intervention crowd out voluntary intergenerational transfers? Will grants be more or less affected than support? What will be the net effect on welfare?

The remainder of the paper is organized as follows. In Section II we introduce the underlying overlapping-generations model on which our experimental study relies. The benchmark behavior as implied by perfect and efficient consumption smoothing as well as by pure selfishness is derived. We also discuss our behavioral hypotheses. After describing the experimental procedure in Section III, the results are presented in Section IV. Concluding remarks in Section V summarize our major findings.

\section{The Model Structure, Main Hypothesis and Related Questions}

In the overlapping-generations model that forms the basis for our experiments we allow for two families. Each family consists of a sequence of generations. One individual represents a generation of a family, and the generations of each family partially overlap. Individuals live for two periods. In the first period, they receive a fixed (labor) income $Y$, in the second period they receive no fixed labor income. Instead they receive a flat pension benefit, financed from contributions by the then young individuals, possibly supplemented by a voluntary transfer from one's successor. Payoffs to each individual are equal to the product of the consumption levels in the first and second periods of one's life. Hence, there is a strong incentive to try and 
smooth one's consumption over the two periods. Given the primary income distribution and the absence of a savings possibility, perfect consumption smoothing can only be achieved by means of transfers.

In the first period (when young) individuals make two decisions. First, they decide how much of their income they wish to transfer to their parent who is presently old. This amount is called the (old-age) support. Second, they decide how much of their income they wish to invest in their child. This investment is called the grant. Grants raise the child's income in the next period and thereby also the mandatory pension tax that is levied on this income. Tax receipts from the young are distributed equally over the present old generation. Hence, grants increase not only the income of one's child, but also one's own pension benefit and the pension benefit of one's contemporary in the other family.

To introduce the notation, let index $t$ refer to generations $(t=1, \ldots, T)$, and let index $i$ refer to families $(i=1,2)$. We then define $G_{t}^{i}(\geqslant 0)$ as the grant that generation $t$ of family $i$ gives to generation $t+1$ of family $i$; $S_{t}^{i}(\geqslant 0)$ as the support that generation $t$ of family $i$ gives to generation $t-1$ of family $i ; C_{j, t}^{i}$, for $j=1,2$, as the consumption level of generation $t$ of family $i$ in the $j$ th phase of life; $u_{t}^{i}$ as the payoff (or utility) of generation $t$ of family $i$; and $P_{t+1}$ as the pension received by (all families of) generation $t$ when old.

The flow diagram in Figure 1 describes the direction of the flows of transfers in the experiment. Note that grants are from old to young, while

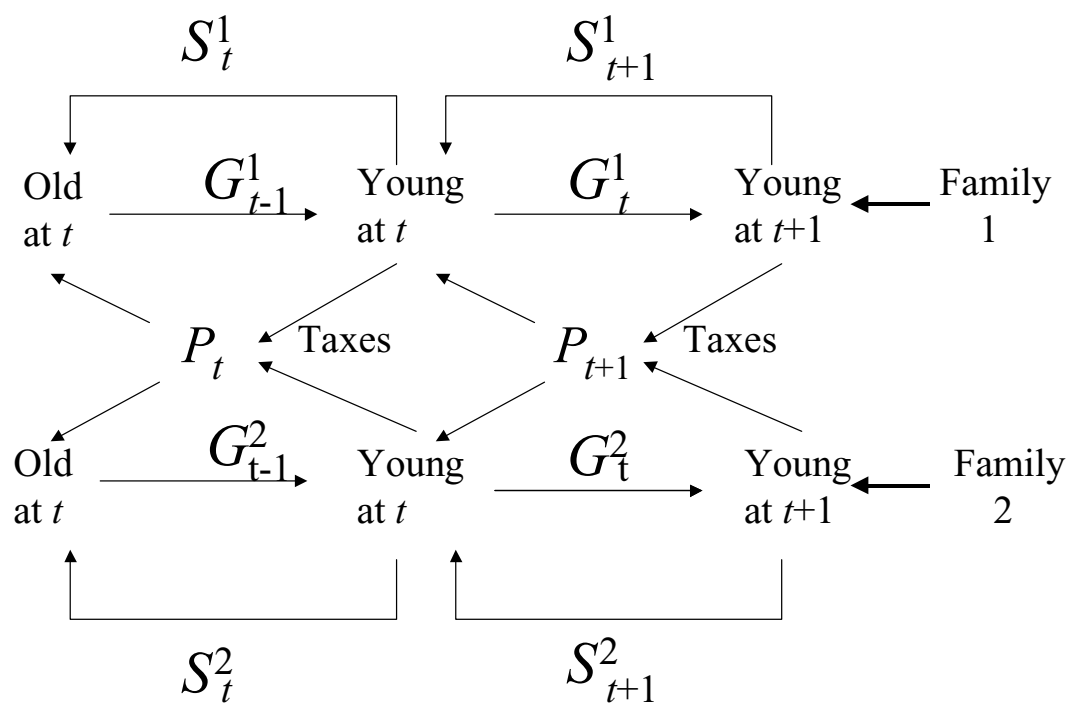

Fig. 1. Flows of transfers within and between families 
support and pensions imply a transfer from young to old. The taxes to be paid by every individual when young are proportional to exogenous labor income plus the grant received from one's predecessor, while every old individual receives a flat pension benefit. So, the PAYG system can lead to redistribution between the two families.

The basic structural relationships are:

Intertemporal payoff function of generation $t$ of family $i$ :

$$
u_{t}^{i}=C_{1, t}^{i} \cdot C_{2, t}^{i}
$$

Consumption level of generation $t$ of family $i$ when young:

$$
C_{1, t}^{i}=(1-\tau)\left[Y+G_{t-1}^{i}\right]-S_{t}^{i}-G_{t}^{i}
$$

Consumption level of family $i$ of generation $t$ when old:

$$
C_{2, t}^{i}=S_{t+1}^{i}+P_{t+1}
$$

Pension of every individual of generation $t$ when old:

$$
P_{t+1}=\tau\left[Y+\left(G_{t}^{1}+G_{t}^{2}\right) / 2\right] .
$$

Here $\tau$ with $0<\tau<1$ is the constant marginal tax rate, and $Y$ is the wage income earned while young (the wage income level of the old is set to 0 ). The other variables have already been defined above.

Equation (1) indicates that the payoff is equal to the product of the consumption levels in the two periods of life. As equation (2) shows, consumption when young is what remains after labor income and grants (from the parent) are taxed and after support (to the parent) and grants (to the child) are subtracted. Equation (3) indicates that consumption when old is equal to the sum of the support received from the next generation (one's child) and the collective pension benefit. Equation (4) defines the pay-asyou-go pension. Incomes of both families of generation $t+1$, including the grants, are taxed and redistributed equally over the two families of the preceding generation (who are now old).

Starting from the above model, two benchmark outcomes naturally suggest themselves. The first is where no voluntary intergenerational linkages exist. If future choices do not depend on present ones, then generation $t$ of family $i$ has no incentive to support its parent, so the optimal decision is $S_{t}^{i}=0$ for $i=1,2$ and $t=1,2, \ldots$. Anticipating this leaves only one reason for a positive grant, namely consumption smoothing via the pension system. By means of a positive grant $G_{t}^{i}$ generation $t$ of family $i$ increases 
the income of generation $t+1$ of family $i$ when young and thus the pension $P_{t+1}$, as defined by (4), which generation $t$ of family $i$ receives when old. It is easily verified, ${ }^{1}$ however, that this does not justify positive grants and, hence, that every stationary and symmetric equilibrium implies $G_{t}^{i}=0$ for $i=1,2$ and $t=1,2, \ldots$. The intertemporal payoff in this case can be seen to be equal to $u_{t}^{i}=\tau(1-\tau) Y^{2}$.

As an alternative benchmark we consider the most efficient stationary means of consumption smoothing, that is, $C_{1, t}^{i}=C_{2, t}^{i}$. The intertemporal payoff in this case can be seen to be equal to $u_{t}^{i}=0.25 Y^{2}$, which is larger than the payoff for the non-cooperative outcome. Under the condition that $S=S_{t}^{i}$ and $G=G_{t}^{i}$ for $i=1,2$ and $t=1,2, \ldots$, perfect consumption smoothing leads to the following condition in terms of $G$ and $S$ :

$$
S+\tau G=(1-2 \tau) Y / 2 .
$$

According to equation (5) there exists a continuum of $(S, G)$-constellations allowing for efficient stationary consumption smoothing. Note, moreover, from (5) that for any value of $\tau<1$, if subjects were to rely merely on grants, these would need to take on much larger values than if they were to rely on supports only.

The treatment variable used in our experimental study is the tax rate, distinguished by two levels: the low tax rate $\underline{\tau}=0.05$ and the high tax rate $\bar{\tau}=0.25$.

Our main hypothesis concerns the effect of the level of the public pension scheme on the level of private transfers. It hypothesizes that more compulsory transfers, i.e., a larger tax rate, will crowd out voluntary transfers. The main reason is that collective consumption smoothing is a perfect substitute for private consumption smoothing. ${ }^{2}$ But this does not imply that private transfers will be fully crowded out. This would only hold if realized levels of private transfers are at their optimal level (equation (5)). Apart from the crowding-out hypothesis, our experiment allows us to investigate a number of related questions. We pose them as questions rather than hypotheses, since arguments on either side of the issues can be advanced.

\footnotetext{
${ }^{1}$ The result follows from $\partial u_{t}^{i} / \partial G_{t}<0$ which, using $S_{t}^{i}=0$, is equivalent to $(1-\tau) G_{t-1}^{i}-G_{t}^{j}-Y(1+\tau)<2 G_{t}^{i}$ for $j \neq i$. Since, in a stationary equilibrium, we have $G_{t-1}^{i}=G_{t}^{j}$, the condition simply requires $-Y(1+\tau)<G_{t}^{i}(2+\tau)$ which holds for all grants $G_{t}^{i} \geqslant 0$. Hence, $S_{t}^{i}=0, G_{t}^{i}=0$ describes a subgame-perfect equilibrium.

${ }^{2}$ As noted in the Introduction, if altruism were the driving force behind both grants and support, then we would expect an increase in grants to compensate the child for the higher tax burden. However, support would definitely decrease as the old are better off with a higher pension benefit.
} 
Crowding-out Hypothesis.: The higher tax leads to lower total levels of support $S_{t}^{i}$ and grants $G_{t}^{i}$.

Related Questions: (a) Will the level of support exceed the level of grants? (b) Will support or grants be more susceptible to crowding out? (c) Will the higher tax rate lead to a higher or lower efficiency gain of voluntary transfers?

The crowding-out hypothesis does not specify what will be used more, grants or support. On the one hand, as noted above, support is more effective as a means of smoothing consumption than grants. This suggests that levels of support will be higher than those of grants. On the other hand, support is directed towards the parent, who by definition cannot reciprocate. It is the child who will have to reciprocate. Sustaining a consistent level of support thus relies on indirect reciprocity, which may come less naturally to people than direct reciprocity. The latter requires the use of grants. Moreover, an advantage of a grant is that, even if it is not reciprocated by the child, it automatically smooths the parent's own consumption to some extent. A grant raises the child's income and thereby future tax revenues and one's own old age pension. There is always some direct positive feedback of a grant, which is not true for support. So, it cannot be unambiguously hypothesized whether the level of support will be higher or lower than the level of grants.

A similar prior ambiguity holds for the question of whether support or grants will be affected most by an increase in the tax rate. As noted above, due to the collective pension scheme, grants - contrary to support-lead to some direct consumption smoothing. This direct benefit, though not sufficient to make grants individually rational, increases with the tax rate. This may mitigate the crowding-out effect of grants. At the same time, this same feature may erode the force of direct reciprocity. It is now less clear that a grant is intended to help the recipient (child) rather than the giver. The potential force of indirect reciprocity is less affected by an increased tax rate. Another feature which affects grants more than support is the free-rider problem. The higher the tax rate, the higher the extent to which grants "leak away" to the other family.

Finally, even though public transfers may crowd out private transfers, this does not imply that a higher tax rate reduces the level of consumption smoothing that is realized through private transfers. For one thing, with a higher tax rate grants become more effective as a means of smoothing consumption. To examine the net effect we compare realized efficiency gain, $R_{\text {eff }}$, defined as the increase in the actual payoff over the payoff generated with zero transfers, expressed as a percentage of the maximal increase in payoffs.

(C) The editors of the Scandinavian Journal of Economics 2002. 


\section{Experimental Procedure}

In the experiment we relied on two families $(i=1,2)$ and sequences of five generations $(t=1,2, \ldots, 5)$. The experiment was performed at Tilburg University, The Netherlands, in December 1997. An announcement in the university bulletin invited students to participate in a decision-making experiment that would earn them money. Subjects were informed that there were two families and a sequence of generations. The number of generations and their place in the sequence was not revealed to the participants. To play a sequence of rounds with two families and five generations, we would need only 10 subjects. When conducting the experiment, however, we actually ran two or three independent sessions at the same time. This prevented the subjects from inferring the lengths of the queues from the number of subjects present in the laboratory. Six sessions were run with tax treatment $\underline{\tau}$ (60 subjects) and five sessions were run with tax treatment $\underline{\tau}$ (50 subjects), giving us 11 independent observations in total.

The decision variables of generation $t=1,2, \ldots$ of family $i=1,2$ are the variables $G_{t}^{i}$ and $S_{t}^{i}$, i.e., its grant and its support. ${ }^{3}$ The sum of these two (non-negative) variables was restricted to be less than or equal to net income, inclusive of grants received. In addition, each generation $(t=1,2, \ldots)$ of each family $(i=1,2)$ was also asked to specify its expectations concerning $S_{t+1}^{i}$ as well as $P_{t+1}$. That is, subjects were asked how much support they expected to receive from their child and how much pension they expected to receive from the collective scheme. When making decisions and specifying expectations, generation $t$ of family $i$ was informed about the following historical variables: $G_{t-1}^{i}$ (grant received from parent), $G_{t-2}$ (grant parent received from grandparent), $S_{t-1}^{i}$ (support by parent to grandparent) and $\mathrm{C}_{1, t-1}^{i}$ (consumption level of parent when young). ${ }^{4}$

In the experiment the fixed gross income when young $(Y)$ was set at 20. Recall that tax rates in the two treatments were $\underline{\tau}=0.05$ and $\bar{\tau}=0.25$, respectively. With grants $(G)$ and support $(S)$ equal to zero, this would give a payoff $\left(u_{t}^{i}\right)$ of $19(19 \times 1)$ and $75(15 \times 5)$ in treatment $\underline{\tau}$ and $\bar{\tau}$, respectively. Optimal consumption smoothing, on the other hand, would secure a payoff of $100(10 \times 10)$ in either treatment.

Except for starting $(t=0)$ and stopping $(t=6)$ conditions, ${ }^{5}$ each generation $(t=1, \ldots, 5)$ of every family $i$ encountered the same type of situation.

\footnotetext{
${ }^{3}$ In the experiment we did not use expressions like parent, child or family but refered to predecessors, successors, and queue.

${ }^{4}$ The last three of these variables could be retrieved only after a (registered) mouse click by the participant.

${ }^{5}$ The relevant choices for the generation before the first one $(t=0)$ and the generation after the last one $(t=6)$ were predetermined by the experimenters (but not revealed to the subjects). The starting and stopping values that we used are: $G_{-1}^{i}=4, S_{0}^{i}=G_{0}^{i}=S_{6}^{i}=3$.
} 
We refer to each series of successive plays by the five generations of both families as a round. To allow for learning, subjects played five or six successive rounds. At the beginning of a round, subjects were randomly (re)assigned to a family and a generation. This minimizes repeated game effects. Although repeated game effects and the possibility of punishment may play a role in many family decisions, as in Peters, Ünür, Clark and Schulze (1999), grants and old age support are to a large extent once-only decisions. Once you decide not to support your parents when old, there is no second chance. In the experiment we wanted to retain this feature.

The sequence of events for a subject in a round is as follows: (0) waiting screen; (1) screen lights up, giving historical information (see above), and asking for decisions about support and grant; (2) after decisions are entered, subject is asked to state expectations regarding support and pension; (3) as soon as the next generation has made its decisions, a screen lights up with support and pension received, and the corresponding earnings; (4) after confirmation the round ends and the waiting screen for the next round appears.

We anticipated that the subjects would find the experiment rather complicated. Therefore, we made sure that the subjects had plenty of time to go through the instructions, ask questions and practice with the time structure of the game and the relation between decisions and payoffs. In total, sessions lasted between $2 \frac{1}{2}$ and 3 hours. About $1 \frac{1}{2}$ hours was reserved for instructions, questions and individual practice. As indicated by a post-experimental questionnaire and conversations with subjects, we were successful in explaining the game to the subjects; 93 percent stated that the instructions were clear.

\section{Experimental Results}

\section{Main Hypotheses and Related Questions}

Table 1 reports the average levels of transfers, the corresponding payoffs and the realized efficiency levels. The bottom row gives significance levels of Mann-Whitney tests of the difference between the two treatments (with the

Table 1. Average levels of grants $G$, support $S$, realized payoff $u$, and efficiency $R_{\mathrm{eff}}$

\begin{tabular}{llllc}
\hline & $G$ & $S$ & $u$ & $R_{\text {eff }}$ \\
\hline$\frac{\tau}{\bar{\tau}}$ & 3.90 & 1.53 & 50.9 & $39.4 \%$ \\
$p$-values & 2.19 & 1.01 & 92.8 & $71.7 \%$ \\
\hline
\end{tabular}

(C) The editors of the Scandinavian Journal of Economics 2002. 
11-session averages as observations). In line with the crowding-out hypothesis, we find that forced redistribution by a system of higher taxes leads to lower levels of grants and supports. Crowding out is far from complete, however. The higher tax rate increases forced redistribution $(P=\tau Y)$ from 1 to 5 . The reduction in private transfers is much smaller than that.

Crowding-out Hypothesis: In comparison with the low tax treatment, the high tax treatment yields lower levels of grants and support. Crowding out is less than complete, however.

Table 1 also allows us to answer the three related questions.

Related Questions. (a) In both tax treatments, the average level of grants is significantly higher than the average level of support. ${ }^{6}$ (b) The degree of crowding out is larger for grants (44 percent) than for support (33 percent). Furthermore, the decrease in grants is statistically significant $(p=0.004)$, whereas the decrease in support is not $(p=0.117)$. (c) The realized efficiency level is significantly higher in the high tax treatment (71.7 percent) than in the low tax treatment (39.4 percent). ${ }^{7}$

Table 1 indicates that in both the low and the high tax treatment, the average level of grants is higher than the average level of support. There is a tendency for the subjects to rely on grants even though grants are a less effective tool for smoothing consumption. At the same time, we see that the crowding-out effect is larger for grants than for support. Support is more immune to government intervention than grants. This must be due to the combined effect of the free-rider problem and the decreasing importance of grants as a token of direct reciprocity. Support is less affected, suggesting that the relative importance of indirect reciprocity has increased under the high tax rate treatment. We return to this below. Furthermore, both these effects suggest that altruism is not a driving force behind the transfers.

Realized efficiency gain due to private transfers is lower in the low tax treatment than in the high tax treatment. Even though a higher tax leads to lower levels of private transfers, these transfers realize a larger efficiency gain. This is due to the fact that with a higher tax rate, grants become more effective as an income-smoothing device.

\footnotetext{
${ }^{6}$ With a Wilcoxon matched-pairs signed-rank test and session averages as observations, the difference is significant at $p=0.03$ in the low tax treatment and at $p=0.04$ in the high tax treatment.

${ }^{7}$ The average actual payoff of 92.8 (50.9) per subject per round in the high tax (low tax) treatment implies that given a maximum payoff of 100 under efficient consumption smoothing, 71.7 percent (39.4 percent) of the potential gain is realized (i.e., 17.8 out of 25 and 31.9 out of 81 , respectively).
} 


\section{Additional Analyses}

The foregoing analysis abstracts from the dynamics of the transfers over time. The actual dynamics are illustrated graphically by Figure 2, which lists the time sequence of the average support and grants in the natural time order (starting with generations $t=1,2,3,4,5$ of round 1, then of round 2, etc.). What emerges from Figure 2 is that in the low tax treatment, grants and support are relatively stable. In the high tax treatment there is a slight erosion of both support and grants. In addition, over time, grants are unambiguously larger in the low tax treatment than in the high tax treatment, while this does not hold for support. In some rounds, support is higher in the high tax treatment than in the low tax treatment. Furthermore, the average levels of grants and support do not display any trend within a round. That is, the average level of transfers is more or less the same for the first, second, third, fourth or fifth generation within a family. ${ }^{8}$

As regards the reported beliefs about how much support they expected to receive from their successor, in the low (high) tax treatment subjects on average expect to receive $\hat{S}_{t+1}^{i}=2.53(1.85)$, while in fact they receive only $S_{t}^{i}=1.53$ (1.01). Subjects are clearly too optimistic about the support to be received. These results also imply that participants on average give less support to their predecessor than what they expect to receive from their successor.

Table 2 gives Tobit estimation ${ }^{9}$ results on how the level of support $S_{t}^{i}$ is related to the level of grants $G_{t-1}^{i}$ and support $S_{t-1}^{i}$ of the predecessor. These relations are hypothesized to measure direct and indirect reciprocity, respectively. As an additional explanatory variable, the support expected from the successor in the same family $\left(\hat{S}_{t+1}^{i}\right)$ is included. This is hypothesized to measure "anticipated reciprocity", under which participants are motivated to match the support they expect to receive from their successors; cf. Sugden (1984). Similar behavioral relations are estimated for the level of grants $G_{t}^{i}$, though the (theoretical) arguments for these relations are weaker than for support.

\footnotetext{
${ }^{8}$ This also suggests that predetermining some of the values in the experiment (see footnote 5) did not have much of an effect the levels of transfers.

${ }^{9}$ Tobit estimation was used as relatively many observations of the dependent variables are zeros. This holds especially for support in the high-tax treament, where 50 percent of the cases involve a transfer of $S=0$. This implies that a linear relationship is not reasonable and that the truncation of the observations at the lower bound of zero should be taken seriously. In any case, we do not wish to place too much emphasis on the estimation results. The regressions assume independence of all observations, which is not satisfied according to the most rigorous standards (only session aggregates can be assumed to be independent). Moreover, there may be simultaneity in the decisions about the $S$ and $G$, which the Tobit procedure does not take into account. Nevertheless, the estimations yield some interesting results which are indicative of the behavioral regularities in participants' choices.
}

(C) The editors of the Scandinavian Journal of Economics 2002. 

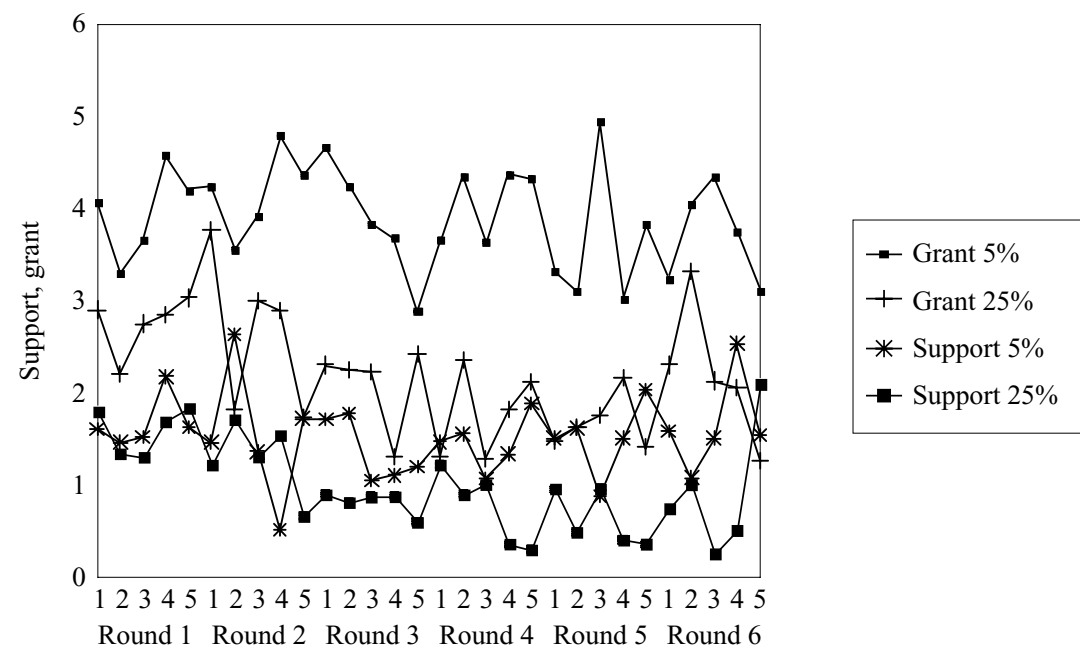

Fig. 2. The dynamics of average support and grants

Table 2. Tobit maximum likelihood results for supports $S_{t}^{i}$ and grants $G_{t}^{i}$

\begin{tabular}{lccccc}
\hline & \multicolumn{3}{c}{$S_{t}^{i}$} & & \multicolumn{2}{c}{$G_{t}^{i}$} \\
\cline { 2 - 3 } \cline { 5 - 6 } & $\underline{\tau}$ & $\bar{\tau}$ & & $\underline{\tau}$ & $\bar{\tau}$ \\
\hline Constant & $-10.65(-2.14)$ & $-779.57(-4.00)$ & & $2.80(6.53)$ & $-5.53(-2.12)$ \\
& 0.02 & 0.00 & & 0.00 & 0.02 \\
$G_{t-1}^{i}$ & $0.44(1.51)$ & $16.54(1.01)$ & & $-0.00(-0.02)$ & $0.58(2.14)$ \\
$S_{t-1}^{i}$ & 0.07 & 0.16 & & 0.49 & 0.02 \\
$\hat{S}_{t+1}^{i}$ & $0.48(1.37)$ & $105.62(3.58)$ & & $-0.21(-2.10)$ & $0.83(2.50)$ \\
& 0.09 & 0.00 & & 0.02 & 0.01 \\
$\sigma$ & $1.16(3.31)$ & $8.93(2.62)$ & & $0.39(5.03)$ & $0.01(0.12)$ \\
& 0.00 & 0.00 & & 0.00 & 0.45 \\
$-\log L$ & $3.70(4.86)$ & $21.04(7.05)$ & & $2.25(16.19)$ & $3.48(6.33)$ \\
Obs. & 0.00 & 0.00 & & 0.00 & 0.00 \\
\hline & 397.94 & 267.01 & & 537.61 & 569.09 \\
& 262 & 174 & & 262 & 174 \\
\hline
\end{tabular}

Note: Estimate standard error in parentheses; $p$-value in italics; for $S_{t-1}^{i}$ we only considered the cases where the former decision was actually looked at by mouse click, which was in 73 percent (64 percent) of the cases in low (high) tax treatment.

From Table 2 we find, first, little evidence of direct reciprocity. The grant received $\left(G_{t-1}^{i}\right)$ appears to have very little impact on the support supplied $\left(S_{t}^{i}\right)$ : while in the low tax treatment some weakly significant effect can be found $(p=0.07)$, in the high tax treatment direct reciprocity plays an 
insignificant role ( $p=0.16)$. Hence, participants do not seem to reward their predecessors with more support when they receive a higher grant. So, although grants are generally larger than support, they do not appear to be very effective as a device for eliciting support.

Second, the strongest signs of indirect reciprocity are in the high tax treatment. Here we find that the support given to the predecessor $\left(S_{t}^{i}\right)$ is positively and significantly affected by the support given by the predecessor $\left(S_{t-1}^{i}\right)$. For the low tax treatment, however, no such relationship is found. This is in line with our result, established earlier, that participants concentrate relatively more on support in the high tax treatment. To achieve this they rely more on indirect reciprocity.

Finally, the support expected from the successor $\left(\hat{S}_{t+1}^{i}\right)$ has a significant impact on the support given to the predecessor $\left(S_{t}^{i}\right)$ in both the low and the high tax treatment. This suggests that subjects to some extent wish to match the support they expect to receive. For grants, $G_{t}^{i}$, the expected support is of importance in the low tax treatment only. This is in line with our earlier conclusion that in the high tax treatment, direct reciprocity will be of less importance than in the low tax treatment.

\section{Concluding Discussion}

In our two-family experiment we have allowed for intergenerational transfers in both directions, i.e., from parent to child, by so-called grants, and from child to parent, by so-called (old-age) support. A compulsory transfer system taxed income of the adults in both families proportionally and transferred the receipts to the old aged of both families in a lump-sum fashion. We implemented a high tax treatment and a low tax treatment. It was hypothesized that a large compulsory tax system would erode voluntary intergenerational transfers (crowding-out hypothesis).

The experimental data were by and large in line with the crowding-out hypothesis. In the high tax treatment, lower levels of grants and support were observed. However, only the difference in grants reached a statistically significant level; crowding out was stronger for grants than for support. Furthermore, in spite of the crowding-out effect, the efficiency of private transfers increased due to the tax increase, and the net effect was clearly positive.

The crowding out of support was not dollar-for-dollar, and grants did not increase, which forcefully suggests that altruism is not the main motive for the private transfers in our experiment. Given the possibility of two-way transfers in our experiments, (at least) two forms of reciprocity could motivate private transfers. One possibility is that subjects provide support conditional on the support provided by their predecessor, i.e., indirect reciprocity. Another possibility is that individuals provide support condi- 
tional on the grant of their predecessor, i.e., direct reciprocity. Grants are a less efficient device for consumption smoothing in our model. Subjects nevertheless did give significantly larger grants than support. This suggests that subjects tend to have considerable confidence in grants as a mechanism for eliciting support. ${ }^{10}$

We did not find much evidence of direct reciprocity, however, and evidence of indirect reciprocity is confined to the high tax treatment. This seems to contradict results from other experiments which do find reciprocity; see Fehr and Gächter (2000) for a recent survey and Seinen and Schram (2000) for evidence of indirect reciprocity. It should be noted, however, that our experiment is more complicated than many others. For example, in many experiments there is only one way to realize gains from cooperation. In our experiment there are many ways to realize such gains. Apart from a cooperation problem there also is a coordination problem. In a more complex environment, acts of kindness are more difficult to "read" and the proper (reciprocal) way to respond to such acts is less straightforward. This does not imply that behavior becomes random; after all, we find some clear and interpretable treatment effects. Since there are different ways to be kind and to support cooperation, however, there is more chance that kind acts are misunderstood and that signs of reciprocity are difficult to detect. ${ }^{11}$

Experiments such as ours provide detailed information on individual behavior and make it possible to isolate the effect of key variables. This paper demonstrates the potential of experimental methods for studying impact of social-security systems on family-based choices. Obviously, as our subjects were students, altruistic motives derived from kinship did not motivate transfer behavior in the experiments. Our study appears to be more in line with the concept of a family as a unit where "family contracts" are conducted "without altruism"; cf. Cigno (1993). We have shown that in the absence of kinship, transfers in a "family-like" context may emerge just as well. Interestingly, in our experiment, we find that the use of grants dominates the use of support, that is, more money flows from "parent" to "child" than vice versa. Such grant dominance is also found in field data, and one might be inclined to relate this to "asymmetric altruism" where parents care more for their children than vice

\footnotetext{
${ }^{10}$ From a post-experimental questionnaire we found that subjects on average expect to benefit more from giving a grant than from giving support. At the same time they believe support to be fairer than grants.

${ }^{11}$ Van der Heijden, Nelissen, Potters and Verbon (2001) drew a similar conclusion based on a gift exchange experiment in which there were different cooperative outcomes.
} 
versa; see e.g. Peters et al. (1999). But as our experiment illustrates, asymmetric altruism and kinship-related motives are not necessary to generate such a pattern; it may even be generated by non-altruistic students as subjects.

\section{Appendix: Instructions (Abridged) ${ }^{12}$}

\section{Choices and Earnings}

The choices that you make, when it is your turn, affect your own earnings. Your choices also affect the earnings of the participant before you in the row of your group (your predecessor) and the earnings of the participant after you in the row of your group (your successor). Furthermore, your choices affect the earnings of the participant in the other group who makes her or his choices at the same time as you do (your contemporary). Conversely, the choices of your predecessor, your successor and your contemporary affect your earnings.

The stage in which you make your choices is called the active stage. After the active stage there is a passive stage. You make two choices during the active stage just like every other participant. First, you decide whether or not you want to give a grant [transfer] to your successor in your group. Second, you decide whether or not you want to give support [overdracht] to your predecessor.

At the beginning of the active stage you get a starting endowment of 20 points. If your predecessor in your group has decided to give you a grant, then your starting endowment [startbezit] is supplemented with this grant. Note that you are the successor of your predecessor, so you receive the grant determined by your predecessor. The resulting amount will be called your gross endowment [bruto bezit]. From your gross endowment you must pay a contribution [afdracht] of 5 percent. Your contemporary in the other group will also contribute 5 percent of her or his gross endowment. This is done to make a general payment to your predecessor and the predecessor of your contemporary. If you subtract your contribution from your gross endowment, you get your net endowment [netto bezit].

Then you can make your decisions. First, you can give a grant to your successor. Second, you can give support to your predecessor. Then follows the passive stage in which you do not make decisions. In the passive stage you may receive two amounts. First, it is possible that your successor will give support to you. Second, you as well as your contemporary receive a general payment out of the contributions by your successor and the successor of your contemporary.

\footnotetext{
${ }^{12} \mathrm{~A}$ full version of the instructions and other material of relevance to the experiment can be found in an earlier working-paper version; see: http://greywww.kub.nl:2080/greyfiles/center/ 2000/54.html.
} 


\section{Schematic Summary of the Experiment}

Active stage

Starting endowment

Grant by predecessor to you

Gross endowment

Contribution (5 percent of gross endowment)

Net endowment

Grant from you to successor

Support from you to predecessor

End endowment 1

Passive stage

Support from successor to you

General payment to you and contemporary from contributions of successors

End endowment 2

$$
\text { Earnings }=0.1 *(\text { end endowment } 1 * \text { end endowment } 2) \text { guilders }
$$

P.S. General payment to you and your contemporary follows from the contributions of successors $=0.5 *[0.05 *(20+$ your grant $)+0.05 *(20+$ grant contemporary $)]$.

\section{References}

Abbink, K. and Sadrieh, A. (1995), RatImage-Research Assistance Toolbox for Computer-aided Human Behaviour Experiments, SFB 303 Discussion Paper no. B-325, University of Bonn.

Altonji, J., Hayashi, F. and Kotlikoff, L. (1997), Parental Altruism and Inter Vivos Transfers: Theory and Evidence, Journal of Political Economy 105, 1121-1166.

Becker, G. (1974), A Theory of Social Interaction, Journal of Political Economy 82, 1063-1093.

Bernheim, B., Shleifer, A. and Summers, L. (1985), The Strategic Grant Motive, Journal of Political Economy 93, 1045-1076.

Bolton, G. and Katok, E. (1998), An Experimental Test of the Crowding Out Hypothesis: The Nature of Beneficent Behavior, Journal of Economic Behavior and Organization 37, 315-331.

Cadsby, C. B. and Frank, M. (1990), Experimental Test of Ricardian Equivalence, Economic Inquiry 29, 645-664.

Cigno, A. (1993), Intergenerational Transfers without Altruism, European Journal of Political Economy 9, 505-518.

Cigno, A., Gianelli, G. and Rosati, F. C. (1998), Voluntary Transfers among Italian Households: Altruistic and Non-altruistic Explanations, Structural Change and Economic Dynamics 9, 435-451.

Cox, D. (1987), Motives for Private Income Transfers, Journal of Political Economy 95, $508-546$.

Cox, D. and Rank, M. (1992), Inter Vivos Transfers and Intergenerational Exchange, Review of Economics and Statistics 74, 305-314.

(C) The editors of the Scandinavian Journal of Economics 2002. 
Fehr, E. and Gächter, S. (2000), Fairness and Retaliation: The Economics of Reciprocity, Journal of Economic Perspectives 14, 159-182.

Gale, W. G. and Scholz, J. K. (1994), Intergenerational Transfers and the Accumulation of Wealth, Journal of Economic Perspectives 8, 145-160.

Hammond, P. (1975), Charity: Altruism or Cooperative Egoism?, in E. S. Phelps (ed.), Altruism, Morality and Economic Theory, Russell Sage Foundation, New York, $115-131$.

Kotlikoff, L. (1988) Intergenerational Transfers and Savings, Journal of Economic Perspectives 2, 41-58.

Künnemund, H. and Rein, M. (1999), There is More to Receiving than Needing: Theoretical Arguments and Empirical Explorations of Crowding In and Crowding Out, Ageing and Society 19, 93-121.

McGarry, K. and Schoeni, R. F. (1995), Transfer Behavior in the Health and Retirement Study (Measurement and the Redistribution of Resources within the Family), Journal of Human Resources 30, S184-S226.

Offerman, T., Potters, J. and Verbon, H. (2001), Cooperation in an Overlapping Generations Experiment, Games and Economic Behavior 36, 264-275.

Peters, H. E., Ünür, A. S., Clark, J. and Schulze, W. (1999), Free-riding and the Provision of Public Goods in the Family. An Experimental Test of the Rotten Kid Theorem, mimeo, Cornell University.

Seinen, I. and Schram, A. (2001), Social Status and Group Norms: Indirect Reciprocity in a Helping Experiment, mimeo, CREED, University of Amsterdam.

Sugden, R. (1984), Reciprocity: The Supply of Public Goods through Voluntary Contributions, Economic Journal 94, 72-87.

Van der Heijden, E. C. M., Nelissen, J. H. M., Potters, J. J. M. and Verbon, H. A. A. (1998), Transfers and the Effect of Monitoring in an Overlapping-generations Experiment, European Economic Review 42, 1363-1391.

Van der Heijden, E. C. M., Nelissen, J. H. M., Potters, J. J. M. and Verbon, H. A. A. (2001), Simple and Complex Gift Exchange in the Laboratory, Economic Inquiry 39, 280-297.

First version submitted October 2000;

final version received November 2001. 